\title{
Highly efficient phenol degradation in a batch moving bed biofilm reactor: benefiting from biofilm-enhancing bacteria
}

\author{
Sahar Irankhah ${ }^{1} \cdot$ Ahya Abdi Ali ${ }^{1} \cdot \underline{\text { Mohammad Reza Soudi }}{ }^{1} \cdot$ Sara Gharavi $^{2} \cdot$ Bita Ayati $^{3}$
}

1 \ Department of Microbiology, Faculty of Biological Sciences, Alzahra University, Tehran 1993891176, Iran

2 Department of Biotechnology, Faculty of Biological Sciences, Alzahra University, Tehran, Iran

$\left.{ }^{3}\right)$ Environmental Engineering Division, Civil and Environmental Engineering Faculty, Tarbiat Modares University, Tehran, Iran

\begin{abstract}
In this study, the efficiency improvement of three moving bed biofilm reactors (MBBRs) was investigated by inoculation of activated sludge cells (R1), mixed culture of eight strong phenol -degrading bacteria consisted of Pseudomonas spp. and Acinetobacter spp. (R2) and the combination of both (R3). Biofilm formation ability of eight bacteria was assessed initially using different methods and media. Maximum degradation of phenol, COD, biomass growth and also changes in organic loading shock were used as parameters to measure the performance of reactors. According to the results, all eight strains were determined as enhanced biofilm forming bacteria (EBFB). Under optimum operating conditions, more than $90 \%$ of initial COD load of $2795 \mathrm{mg} \mathrm{L}^{-1}$ was reduced at 24 HRT in R3 while this reduction efficiency was observed in concentrations of 1290 $\mathrm{mg} \mathrm{L}^{-1}$ and $1935 \mathrm{mg} \mathrm{L}^{-1}$, in R1 and R2, respectively. When encountering phenol loading shock-twice greater than optimum amount-R1, R2 and R3 managed to return to the steady-state condition within 32, 24 and 18 days, respectively. SEM microscopy and biomass growth measurements confirmed the contribution of more cells to biofilm formation in R3 followed by R2. Additionally, established biofilm in R3 was more resistant to phenol loading shock which can be attributed to the enhancer role of EBFB strains in this reactor. It has been demonstrated that the bacteria with both biofilmforming and contaminant-degrading abilities are not only able to promote the immobilization of other favorable activated sludge cells in biofilm structure, but also cooperate in contaminant degradation which all consequently lead to improvement of treatment efficiency.
\end{abstract}

Keywords: Biofilm wastewater treatment, Bioaugmentation, Bioremediation, MBBR, Phenol degradation, Strong biofilm-forming bacteria 